\title{
PERSPECTIVE
}

\section{The uncertainty of modern society in Cambodia: A new perspective of the govern- ment in insurance regulation}

\author{
Chou Meng \\ Koguan School of Law, Shanghai Jiao Tong University, Shanghai 200240, China
}

\section{Check for updates}

Correspondence to: Chou Meng, Koguan School of Law, Shanghai Jiao Tong University, Shanghai 200240, China; E-mail: mengchou77@sjtu.edu.cn

Received: June 13, 2021;

Accepted: August 25, 2021;

Published: September 1, 2021

Citation: Meng C. The uncertainty of modern society in Cambodia: A new perspective of the government in insurance regulation. Soc Work Soc Welf, 2021, 3(1): $148-155$.

https://doi.org/10.25082/SWSW.2021.02.002

Copyright: (c) 2021 Chou Meng. This is an open access article distributed under the terms of the Creative Commons Attribution License, which permits unrestricted use, distribution, and reproduction in any medium, provided the original author and source are credited.

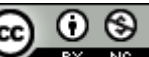

\begin{abstract}
Since the long period of political, social stability and especially the peacebuilding under the interfering of the United Nation, in 1991 the Paris Peace Accord was signed. Cambodia was settled in a peaceful state and it has achieved the basic fundamental for county's economic development with rapidly status. Accordingly, the social protection policy has critically recognized by the government recently, however, whilst the economic gains are more likely fragile, most of the people are still in the poverty line, the long-term economic prospects are uncertain, such as its weak institution, social inequality and unemployment issues, and social protection system. The social protection system in Cambodia, as a particular, is at an early stage, and very limited. With the small proportion of the covered social insurance program, there are lifecycle shocks and economic downturn have resulted. Thus, the role of private insurance (insurance industry) in boosting the domestic financial economy, and its potential in risk management and complement state's social insurance program have become the prime matters of considerable interest to state's regulators and policy-makers.
\end{abstract}

Keywords: Cambodia, social welfare, social insurance, risk management, insurance regulation

\section{Introduction}

Cambodia is a country which has emerged from a long decade of instability, and conflict; at the same time, it has had an impressive long record of sustained poverty reduction and its economic growth. After the "Paris Peace Accord" was signed in 1991, Cambodia had prepared its first general election in 1993. Being a post-conflict country, Cambodia which overall economic growth is depended on the foreign donors and foreign direct investment. Extended to its second national election wherein the political situation is more stable had provided a reliable basis for significant economic growth. Following with this aspect, the current real economic growth rate is around 7 to 7.2 percent, which is driven by some important sectors including garment industries, real properties and housing constructions, and services sectors. After the victory of the third national election by the Cambodian People Party (CPP), the government of Cambodia has issued a significant country's development strategy New Five Years Rectangular Strategy (RS); it had distinct strategies which identifies the major development priorities sectors and challenges. Currently, with the new government thereby won the national election in July 2018, the Royal Government of Cambodia continues its Rectangular Strategy (path IV). With a more specific development and very detailed action plans which linked to the priorities sectors and the strong monitoring system provided in the Rectangular Strategy would be an effective tool to address the development challenges and meet its goals [1].

Even it has been a country under the world's fastest-growing economies in wherein the foreign trade and investment (direct investment) [2] and commercial policies are very open, its macroeconomic policies are in good condition, however, Cambodia still facing many serious problems, such as its weak institution, social inequality and under-employment issues, and social protection system. The social protection system in Cambodia, as a particular, is still very limited. In modern society, the social protection system means about the government security program, social welfare, and social insurance system. Friederike Lenel and Susan Steiner in their research demonstrated that, in Cambodia, only the civil servants enjoyed the social welfare wherein provided by state's National Social Security Fund; some of the non-governmental organization's staffs enjoyed the private insurance [3]. Insurance is the primary importance of financial service in not only international economies, but it, too, very important in domestic economies. While insurance has become more importance in the development of a state's financial institution due to the increase in the risks and uncertainties in current Cambodia's 
society. However, unlike its neighbor counties, Cambodia's insurance market is still in an under-developed country [3] (UNDP 2013; Micro-insurance Network 2016). The conception of insurance is affected the state's public interest as significant goods or services whereby serve the public's interest. Accordingly, the terms and conditions stipulated in the sold insurance including the charged premium should be subject to regulation to serve the interest of consumers At the same time, the role of an insurance company in the financial economy and its potential in risk transferring system should be a matter of policy-makers and regulators to consider to serve the public interest.

This article will examine the context of uncertainty and vulnerability of risk management in Cambodia as the point of view that the state should consider governing the insurance regulation, and potential reform to serve the public interest. In addition, the paper also offers some basic economic principles which play a crucial role in the process of economic development and could boost the improvement of the financial institution. It noteworthy that, the insurance regulation has been stipulated since 1992, and has been adding to the state's reform strategy (Rectangular Strategy) since 2004. Due to well-functioning of insurance have a vested interest to the public and national economic prosperity, there are compelling reasons to advocate for reforming the insurance regulation thereby economically sound and could effectively promote an efficient insurance market.

\section{Overview of the historical context of the insureance industry}

\subsection{General context of insurance}

It is very hard to define what insurance is since it is a complicated and intricate mechanism. Nevertheless, in its simplest aspect, insurance has three fundamental unique features: risk allocation, risk transfer, and loss-spreading. When a person (insurer) has a responsibility or obligation to settle or indemnify the other person (insured) against any losses or claims while the insured events occurred is a kind of risk allocation. One person (insured) would be facing a risk and he transfers this risk to another party (insurer) by contracting (insurance) in exchange by paying the premium. The subject of contracting is to shift the risk the other party (insurer) is called risk transfer. In the same condition, while the insured incident occurred and caused losses to insured, the insurer has to compensate to the insured all or a part of the losses according to what they agreed in the contracting term. This is a loss spreading in the insurance context [4]. For the whole society, insurance plays a significant role to effectively provide security to the public and reduce stress in society. It is a potential mechanism to reduce the risk in the life of public; however, this not means that it could be banned or prevent the public to take the risk, but it could decrease the risk by reducing the loss, damage which would occur in life. The Risk is arising everywhere in society, and risk is always following everyone in their life. Life is about to challenge and to take risks. People have the right to take a risk, and in some countries to challenge the risk is a unique culture and in particular place, it is recognized as a political tradition, as such in America, the satisfying and challenging in life will be missing without risk [4].

Furthermore, insurance, at least in an individual point of view, is a high potential economic device wherein he/she could obtain a large amount of money (indemnify by the insurer) by substitute a small amount of paying in advance (premium) [5]. In this context, for an individual, insurance plays an important role as a counterpart of risk, which known as a security; it is provided a financial security to an individual by preventing and reducing [6] their amount financial loss when the uncertainty event occurred. As a matter of this, the further development of insurance should be considered as to serve the protection of public security, and the market of insurance should also offer more appropriate products.

\subsection{Beginning of Cambodian insurance market}

An understanding of the trend of Cambodian insurance market depends on its historical context. It will provide a baseline for understanding the progress and hinder that Cambodian market has been gone through, and it would be a helpful way to identify the culture force and society demand wherein the insurance is a necessary mechanism in modern society.

The beginning of the insurance industry in Cambodia does not have a long history like others countries in the region, and in an erratic condition whilst it did not play a good function on market at that time. In the mid-18th century, under the protectorate and colony by French, and with 
the expansion of trade and initial of industrialization lead by French, some western insurance branches had emerged in Cambodia. Following the county's economy and administrative matters were governed by French, this formalized insurance market, too, is occupied by French [7]. After the end of the French colony, the first insurance business established in 1956; there are some insurers served the market demand and all of them were under the joint-venture status. However, the state had bought the private share back in 7-year later in 1963 (Ministry of Economic and Finance, 2009). In order to adjust the operation of the market, in 1964 the government enacted the "Law on Monopoly". Accordingly, the Societ National d' Assurance (SNA) had become a monopoly company which served in the whole market. A few years later, after the took controlled by the Democratic Kampuchea (DK) or Khmer Rouge (KR), the country's infrastructures, financial systems, and industrial market were destroyed, abandoned and closed; no commercial affairs were transacted, particularly the insurance transaction. The communist ideology and program involved in society by the Khmer Rouge eroded deeply in many aspects of the county's economy. Whilst there is no private ownership of property, no freedom of movement, no markets transaction and the comprehensive closed of trade inflow, thus, too, there is no needed for insurance.

\subsection{Current market trends and its growing perspective}

After the collapsed of the brutality of the Khmer Rouge, the country almost remains nothing besides the survivors of the genocidal regime with deeply emotional and physical exhausted. People suffered from hardship and terror executive, this is a time that they remember as the time of lvinh-chu-chot (the sharp testes of unripe fruit) [8]. Under the rule of Khmer Rouge, Cambodian society and economy were deeply traumatized with the bitter test of civil war. Then, after the victory in 1979, we are, Cambodia has to start our country from the zero bottoms (Year Zero).

With the Government's reform policies on economies and financial sectors, the resumed of the insurance market began in the 1990s (Sub-Decree No. 24 RNK on 20 September 1990). Since the restitution of the insurance market, the Cambodian National Insurance Company (CAMINCO), under the state-owned enterprise status, had been taking the monopoly market in Cambodia since 1990 till 1996. The CAMINCO had special characteristics while it was monopolized the market and was granted the power the supervised the whole market's operation. There are very few insurances needed during these periods, and almost the insurance consumers are foreign traders and the Non-Government Organization's staffs. Until 2001, the government decided to convert CAMINCO from state-owned enterprise to public enterprise; however, it is still the only insurance supplier in the market. A year later, another Re-insurance company had joined the market. The Government of Cambodia, with its opening policies and the goals of boosting national economic development, had moved forward in industrial reform, particularly, privatize the insurance industry. There is no monopoly anymore in Cambodian insurance sector. Accordingly, the joint ventures and/or sole foreign-owned status firms have been allowed to run businesses in the insurance market. From the early 2000s onwards, the insurance development in Cambodia was noted as the watershed period, while the premium revenue of insurance was greatly increased from US\$8.8 million in 2003 to US\$12.14 million in 2006 [9].

By comparing with its neighbor countries, Cambodia was ranked as the slowest one in insurance development. However, even the Cambodian insurance industry is still in its fancy stage, but it has a great room for future growth. As stated by the Insurance Association of Cambodia, the growing of insurance premium has a great notice point. The annual growing is at $19.7 \%$ annually, and the total market premium has been growing rapidly from US\$ 8.8 million in 2005 to US\$ 60 million in 2014. In 2006, as part of efforts of the Government of Cambodia to modernize the nation's economy, "The Financial Sector Development Strategies (FSDS) for 2006-2015" was adopted in which to boost the development of state's financial system in general, and to identify the improvement of the insurance industry in particular. With the consent of this reform strategies, and accompanying with political and economic changes, had increased the insurance participants. Following with this trend, the flow of foreign investment into Cambodia is increased enormously, then the needed of insurance protection also grew. It required foreign own enterprises and joint ventures to purchase insurance from domestic insurers. Thus, the growth of the economy through foreign investment created more demand for insurance in the market. So far, the insurance suppliers have been increased; there are 28 insurances companies, including 12 general insurances, 7 life insurances, 1 re-insurance and 8 micro-insurances, and with 4 insurance agents [10]. Consequently, though the market is quite small, yet it has great potential to experience growth. Thus, the future development of the insurance industry is thoroughly depending upon the wills of the government, and if so, the regulatory measures by the government are necessary. 


\section{Faster economic growth with the lack of risk man- agement and insurance}

\subsection{Modernization of socio-economic with lake scheme of social welfare}

The State of Cambodia is one of the smallest countries in the region, and the poorest one in the world [2]. Cambodia has a complex social and political transformation, though, since 1992 its economy has been growing rapidly with an average of $7 \%$. Thereafter, since it got the full peace, Cambodia has entered into its new developing era; both domestic and foreign investment trades are opened. By implementing new economic development policies and enlarge the capital inflow of foreign investment, Cambodia has become the most welcomed investment and the fastest economic growth in the region and the world. Thus, it was recognized as one of the world strongest and most sustainable economic growth [11]. Following with the Government's development strategies: "The Rectangular Strategy (2004)" (Royal Government of Cambodia, 2004), "The Strategic Framework for Development Cooperation Management (2006)" (Royal Government of Cambodia, 2006), the expanding of domestic economic ties with ASEAN member states and others trade preferential from the WTO's members, Cambodia's GDP has grown rapidly with $7.8 \%$ in average between 2000 to 2015 . Accordingly, the GDP per capita also raising to US\$ 1225 and the country's poverty rate has decreased from $21.8 \%$ to $2.2 \%$ by 2014; and by July 2016, it officially qualifies as the lower-middle income country [11].

The country's economic prosperity in recent years is growing rapidly, however, many major uncertainty challenges still remain. First, it is still in the status of world's least developed countries, whilst a large number of its population is in poverty status, especially in rural areas. Second, its political condition and institutional features are very weak and classified as a quasi-authoritarian state with fragile institutions [2]. Third, the widespread of the informal and vulnerable of young employment issues. And fourth is the uncertainty of social security and personal welfare.

What is 'uncertainty' here mean to society? Sir Brian Corby acknowledged that: " "uncertainty' means that we cannot be sure of the future, or that the consequences of action or non-action depend on developments or situations which are neither controllable nor known in advance." [12] These uncertainties in society could very possibly be caused many risks to the public in general, and to the individual in particular. A Risk is the probability of the occurrence adverse events at an unpredicted period and it obviously produces harms and loses. From the dawn of civilization in a modern society, all human activity involves risks and faces a high possibility of loss. In many post-conflict economy states such as Cambodia, people are facing many uncertainty life conditions. Whilst the state is under the process of development, there is much unrealistic social security, for example, the unusual unemployment, low social welfare package, and insufficient risk management.

\subsection{Brief context of public social welfare in Cambodia}

The initiated of public social welfare or social protection system in Cambodia has been implemented since 1993 . The range of social protection means had explicitly confirmed in a number of Government Strategies, including the first Social-Economic Development Plan of 1996-2000 (SEDP), second SEDP of 2001-2005, the first National Strategic Development Plan of 2006-2010 (NSDP), the second (updated) NSDP of 2008-2012 (18 OECD Development Pathways, 2017). Thereafter, recently in 2017, the Government of Cambodia had published its Social Protection Policy Framework of 2016-2025 (SPPF) (Royal Government of Cambodia, 2016); this framework lays the major foundation of the county's integrated social protection system. This is the first official policy document of the government of Cambodia wherein covered the state's social assistance, social insurance, and social health protection to its people. This policy establishes 6 main goals. First, to implement new social assistance program by expanding the scheme coverage; second, expanding social security to the goal of universal coverage for social health care and social pensions; third, reexamine the institutional allocation to establish National Social Protection Council; fourth, enhance the investment environment for social protection; fifth, integrate identification and registration systems; and sixth is to promote citizen awareness on social protection [11].

The right to social protection is granted by the constitutional law of Cambodia in article 36; it establishes that the Cambodian citizens have the right to obtain social security and other legitimate benefits provided by existing law and regulations (Cambodian Constitution, 1993). Other three special laws also play a significant role and provide a legal basis for a citizen in 
accessing to social security: The Labor Law (1997), The Law on Insurance (2014) and the Law on Social Security Scheme of Persons (2002). However, the current system is still in limited conditions. At present, the social health care is still weak, for example, a small amount of people is covered by the social health care project (Health Equity Fund), and most of them are identified as in poor status (IDpoor). By comparing with other countries in ASEAN region, Cambodia is classified as the second-lowest after its counterpart Lao PDR [11]. On the one hand, its social insurances are in fancy step. The scope of social insurance is very limited and until now only the staffs or official from formal-sector could access to health insurance system and other employment injury indemnify. The state's civil service officers and militias and other informal sector's staffs did not get any health insurance coverage.

The social assistance in Cambodia has been confirmed in too low status. As the confirmed data given by the National Social Security Fund of Civil Servants and the National Fund for Veterans, the pensions for disability, retirement and death only arranged for the civil servants and military officer. Yet, the covered schemes still in limited, and it only granted to the one who had registered in the last 20-year and had paid at least 60 months during the last 10-year (Until 2016, only 180000 civil servants and 87500 police and armed forces staff was covered the policy schemes). There is no pension policy covered in private sectors, yet only Employment Injury Insurance (EII) has been covered. The scope of EII has covered only the temporary disability (The benefit from temporary disability is equivalent to $70 \%$ of the worker's salary) and permanent disability (The benefit of permanent disability is depending on the actual degree of disability and the age of the worker), and funeral costs whilst the worker death. Consequently, Cambodia under the government's efforts in recent years, the improvement of social security and welfare has been well-noticed. However, while it still in its fancy status and the scope is too small, thus, it is still not too consistent with the current social needs.

\subsection{Missing gaps in private sectors, individuals' risk management, and social security}

In today modern society, all human activity is involving many risks. Likely as a few years ago Professor Raymond Barre, the former France Prime Minister acknowledge a question that:

"We are living in a world where uncertainty is growing and risks are becoming ever more extensive. At the same time, we note an upward trend in the demand for security. To what extent can the demand for security be met by the State without slowing down or hindering the adaptations made necessary and inevitable by the far-reaching changes taking place in the world?" [12]

We as a human being, taking risk constantly in our everyday life, including individual, public and other organizations (including business entities). For an individual, as we discussed above, not all, but at least, their risk is covered by the state's social security system. However, a large number of public and business entities are not covered by the scope. As Sir Brian Corby emphasized, the democratic society, freedom, and uncertainty are going together; and risks are inseparable, whilst the choice implied, then the uncertainty will come in turn [12]. It is very suitable to affirm that, the world we live is riskier day by day; and whilst the elimination of the risk is not possible, we, then have to accept and learn how to manage it. In the industrialized countries, most in the western world, are making a great effort and rightly ways to reduce their involvement in the economic life of its society by transforming the risk through risk management (insurance) mechanism to the private sector (insurance firms). As in the United State, the private insurance plays a significant role in social risk management. In American people perspective, the insurance coverage is a substantial part of their security needed, social protection and would give them peace of mind. This is, therefore, being a vital tool of the government of seeking to establish a suitable mechanism to manage uncertainty and reduce the risk of the public. The risk the private insurance (insurance company) faces is not only the risk transferred by the individual insured but also from the risk or liability spreading from the other business entities. For example, the business entity's property insurance or their staff' life insurance. This is not mean that the insurance is an attempt to get rid of the risk, although is to limit the damage it would be; as no one can prevent from dying, yet the insurance could make one's departure more bearable and peace of mind.

In Cambodia, both the social insurance provides by the government and the private insurance sectors are constantly increased, however, the scope of insurance is still in limited status. Thus, it is very clear that the people are unable to acquire a standard living following the current country's development. Meanwhile, according to the present trend in society, many problems of uncertainty are produced and caused the public uncomfortable. Therefore, private insurances will play a great role in today's Cambodian society; and would be resulted in a strong consensus 
both on social welfare and economic development. For this reason, the state regulation on insurance would be a prime need for the government to consider.

\section{Why state need private insurance?}

The pure form the insurance is social's goods; whilst it serves for the public interest, it is classified as public's goods [13]. Insurance has a very well opposite effect of causing and cost of losses; however, just notice that insurance does not have loss preventing function. From the individual point of view, insurance can eliminate the individual's risk by transferring to the insurer; it reduces the amount costing in uncertain losses by substituting to a certain cost. Another point of view from the social perspective, insurance too, is an economic device to eliminate and reduce the risk by combining it into a group and make a prediction of the amount costing by risk [5]. Hence, in society, insurance is very likely to be the public utilities that have a great affected with the whole interest of the public. Individual life and health insurance, for example, mobilize the saving from a private household sector, business, and public sectors Life and health insurance also provide an accessing to medical care which is the basic goods for individual well-being. Other kinds of insurance would be included as well as auto liability insurance, fire insurance, property destroy liability insurance, unemployment insurance and so forth. The argument for regulating insurance operation is therefore strong, and the government's regulation should be reflected the importance of the public as a whole.

The most significant role of insurance was created and designed both for social and economic activity. As examined by Pro. Kenneth S. Abraham, the insurance operated as a public utility in social [14]. As functioning as a contract, a product, and statute, the insurance policy acting as social instruments in which serve an important function in modern society; it is an effective mechanism of government in reflecting social welfare and domestic economic development. Appreciating with these aspects of insurance can better remind the government in acknowledging the meaning of insurance and future perspective for improving the insurance regulations.

\subsection{Significant role as a public utility in reflecting social welfare program}

From the perspective of social insurance, insurance has been using as a mechanism for transferring and sharing the risk. It provides compulsory protection to the public as a whole, and to individual's risk as particular; the possible loss of asset or income by sickness, disability, accident injury or death are involved. Social insurance very possibly provides a "floor of protection" to the one who's unable to deal with certain risks. It does provide the benefit to the public as a whole, though, in Cambodia, the function of social insurance seems not very appropriate and sufficient.

Therefore, however, the private insurance, with its special function, could substitute and complement the government's role in social insurance. The appropriate insurance industries, at least the more strongly one, with it product types could relieve the pressure on the government's budget on social insurance program spending [15]. The most typically are life insurance, can substitute the government security/welfare program whilst it plays a vital role in personal retirement and health care insurance planning program. Many studies proposed by Beenstock, Dickinson, and Khajuria, and Wasow in 1986, have been confirmed that the great private expenditures on life insurance will reflect the reduction of state's social insurance program expenditures [6]. The complementation of private insurance in the public security program would result in the relieve of state's pressure, therefore then reserving the government's budget to spend on other worthwhile purposes. Additionally, it could also be improving the quality of individual life and increasing social stability. The individual, in general, could freely tailor their security arrangement with the proper necessity and particular need, for example, personal health, accident liability and life insurance [16], pension funds and other worker's compensation.

Additionally, the liberalizing of the private insurance market could benefit the area of government operation of public services to the lower-income public in the rural area such as micro-social insurance plan and social security program. At present time, there are 8 microinsurance companies in Cambodian market: BIMA Cambodia insurance, Cambodian People micro-insurance Plc (CPMI), Forte micro-insurance, H.I micro-insurance Plc, Meada Rabrong Plc, Mekong micro-insurance Plc, Prevoir (KAMPUCHEA) micro life insurance Plc (PKMI), and Prosur micro-insurance Plc (Insurance Association of Cambodia). The Government of Cambodia is working hard to establish the supporting mechanism for micro-insurance in order to widen the scope of insurance to the poor segments in rural areas. Yet, the alternative insurance schemes, as well as the community-based scheme for the public in rural areas still in the lower 
level. Consequently, further promoting mechanism and regulatory environment for ensuring the interests of lower-income populations are taken into account in the insurance sector, the government need to keep up more effort to reach the goals.

\subsection{Significant role for domestic socio-economic prosperity}

In most developed and emerging market countries, the insurance industry, of course, is a very large entity and infrastructural pillar of the financial services sector in particular, and the economy as a whole. Insurance not just only serves for financial compensation of insured's victims, but it also takes part in the central part of the capitalization process in a modern economy. The growing of the financial services, the well-developed the economy has resulted. As suggested by Patrick (1966), the financial sector and economic growth have two existing co-relationship; fist, the financial sector plays a supply leading in economic growth and the economic growth caused by the supply of financial services; two, the demand for financial services can result in the growth of financial institutions and their assets [15].

Therefore, of course, financial services generally and the insurance sector, in particular, is vitally important to domestic economic development. The more growing and efficient the insurance sector, the greater its contribution to domestic economic development it will be. Insurance provides a stable financial of individuals, households, and organizations, for example, anyone buys a home, then he purchases homeowner insurance. Following with the policy clauses in the insurance slip, in case the house is destroyed by other unexpected incidents, thus, therefore, the insurer will indemnify against this peril. As this matter, without insurance, losses could cause the homeowner a financial distress. On the other hand, consider typically about the commercial firm. The firm could very possibly suffer in major financial difficulty or sometimes fail the business when they are failed to insured their business [17]. If, however, such this event occurred, not only the firm itself would lose its stake, or employees too, would lose their jobs, supplies chain lose, products lacking, and consumers lose their competitive prices. This would cause economic distress whilst society lose its future contribution and decrease of tax revenues $[6,16]$.

Another point of view is insurance provide risk transformation reduction and pooling. As a matter of risk, the better the risk management services provider, the greater the saving, more investment environment, and efficiently market involve are allocated. The more effective insurance is, the less unnecessary precautionary saving needed. Then, therefore, insured just only have to secure an adequate cover through a kind of insurance policy by paying a lower amount of premium with the definite period, no other unnecessary insurance covered needed. Hence, they can be allocated their money in other individual investment or any productivity business. Furthermore, in this modern competitive society, many products and services are produced in a very competitive manner. The success of the commercial products in the market depends on the quality of products; then products insurance play a key supporting role [15]. In commercial and trade affairs, are more likely to extend its venture expands if the adequate insurance has insured. It is clear that insurance underpins most of the commercial activities, business transactions and trade affairs. It is not unsurprising. In modern economies, insurance is very possible to save the firm from an uncertain risk which would push into bankruptcy. It is an essential lubricant of commerce and trade; its existence would give the firms the chances to plan ahead their business process with more certainty, with no threatening from specific risks. Consequently, insurance thus plays a special role in underpinning the growth of commerce, trade, and the economy as a whole.

\section{Conclusion}

The lesson of this article is that employing the conceptions of private insurance in social insurance, public welfare and economic development's role as the evidence of the argument in motivating the modernization of insurance regulation. However, insurance sectors, unfortunately, are considered as an unnecessary expense by some potential buyers, and at least some cannot afford. This is wrong to think that insurance is unnecessary. Insurance serves a vital function of the social security in general and personal protection mechanism in particular, and in domestic economic prosperity. Whilst the individuals and other firms have a demand for security, the balanced judgment should be taken in a capable way of being addressed by the government to fulfill. In many developing and emerging countries and Cambodia as well are facing many unexpected sever natural catastrophe risks and uncertainty events in daily life. Thus, therefore, Cambodia with the poor development of the state's social security/insurance can limit the chances to transfer the risk of individuals, households and other firms. The total certainty or 
security seems has no way to achieve. With the failures, experiences and disappointments in this system could lead us to be ready to change the system. It would be the right way to consider regulating the insurance regulation. After all the good features that have been written here of the effectiveness and contribution of the insurance industry in the social security and modern economic development, the efficient regulatory system of insurance sector should be considered and must be subject to serve the public interest.

\section{References}

[1] World Bank Group, H. Clear Skies: Cambodia Economic Update, 2004.

[2] Hill H and Menon J. Cambodia: Rapid Growth in an Open, Post-Conflict Economy. Asian Development Bank Working Paper, 2014, 12: 1649-1668. https://doi.org/10.1111/twec.12206

[3] Lenel F and Steiner S. Insurance and Solidarity: Evidence from a Lab-in-the-Field Experiment in Cambodia. Presented at The Institute of Labor Economics, 2017.

[4] Markin R and Steele J. Insurance and the Law of Obligations. Oxford: Oxford University Press, 2013. https://doi.org/10.1093/acprof:oso/9780199645749.001.0001

[5] Vaughan EJ and Vaughan T. Fundamentals of Risk and Insurance, John Wiley \& Sons, Inc. 2008.

[6] Skipper Jr KD and Klein RW. Insurance Regulation in the Public Interest: The Path Towards Solvent, Competitive Markets. The Geneva Papers on Risk and Insurance, 2000, 25(4): 482-504. https://doi.org/10.1111/1468-0440.00078

[7] Chen WH. Research on the Southeast Asia Insurance Market (DONGNANYA BAOXIAN SHICHANG YANJIU). China: China Financial Publishing House. (Chinese), 2015.

[8] David Chandler. A History of Cambodia, 4th Ed. Westview Press Publisher, 2008.

[9] Department of Financial Industry, Ministry of Economic and Finance. Insurance Annual Report 2006-2009, 2009.

[10] Cambodian Insurance Association, 2018. http://www.iac.org.kh

[11] OECD Development Pathways, H. Social Protection System Review of Cambodia. OEDC Development Centre. 2017.

[12] Corby SB. On Risk and Uncertainty in Modern Society. The Geneva Papers on Risk and Insurance, 1994, 72: 235-243. https://doi.org/10.1057/gpp.1994.17

[13] Lester R. Introduction to the Insurance Industry, The World Bank, Primer series on insurance, 2009.

[14] Abraham KS. Four Conceptions of Insurance. University of Pennsylvania Law Review, 2013, 161(3): 653-698.

[15] United Nations Conference on Trade and Development, p. Trade and Development Aspects of Insurance Services and Regulatory Frameworks. Presented at United Nations, Ad Hoc Expert Meeting on Insurance Services, 2005.

[16] Baker T. Insurance in Socio-legal Research. The Annual Review of Law and Social Science, 2010, 6: 422-447.

https://doi.org/10.1146/annurev-lawsocsci-102209-152839

[17] Stempel JW. The Insurance Policy as Social Instrument and Social Institution. William and Marry Law Review, 2010, 51: 1489-1582. 